\section{A REVIEW OF THERMAL INJURIES IN CHILDREN PRESENTING TO A PAEDIATRIC EMERGENCY DEPARTMENT. ARE WE RECOGNISING SIGNS OF INTENTIONAL BURNS?}

\author{
T. Bourke, S. Anzar, A. Thompson, E. Dalzell
}

\section{Royal Belfast Hospital for Sick Children, Belfast, UK}

Aims: $12 \%$ of children who suffer physical abuse have evidence of severe burns ${ }^{1}$. To inform our Safeguarding practice we wished to establish if current documentation of thermal injuries was adequate to identify risk factors for intentional burns.

Methods: 15 risk factors for intentional burns were identified from the literature ${ }^{1,2}$ and a retrospective chart review was performed.

Results: All 72 children who sustained a thermal injury over a four-month period were included. Documentation was inadequate to identify a number of key risk factors including:

- Delayed presentation (25\% inadequate)

- Lack of witness (75 \% inadequate)

- Known to social services (80\% inadequate)

- Previous injuries (90\% inadequate)

- Other current injuries (79\% inadequate)

- $\quad$ Faltering growth (25\% inadequate)

- Passive/fearful/unkempt child (73\% inadequate)

Documentation of the mechanism, agent and physical features of the burns was much better with over $80 \%$ describing these adequately to identify risk factors.

Conclusion: Previous audit in our department has shown that Safeguarding training is adequate. Therefore it is clear that further strategies are required to improve documentation to ensure we are not missing risk factors for intentional burns. We plan to design and implement an evidence based 'Thermal Injuries Proforma' to ensure good documentation and to require all staff to consider the possibility of intentional scalds.
1. Maguire S. A systematic review of the features that indicate intentional scalds in children. Burns 2008;34:1072-1081

2. Greenbaum A. Intentional burn injury: an evidence-based, clinical and forensic review Burns 2006;30:628-642

\section{0}

\section{SICHUAN EARTHQUAKE AND EMERGENCY RELIEF CARE FOR CHILDREN: REPORT FROM THE FIRSTLY ARRIVED PEDIATRICIANS IN THE EPICENTER ZONE}

\author{
J. Zhao, Z. Hu, Y. Shi
}

Pediatrics, Daping Hospital, Third Military Medical University, Chongqing, China

Objective: An 8.0-magnitude earthquake struck Sichuan province of China on May $12^{\text {th }}, 2008$. Over the next 10 days, the firstly arrived uniformed pediatricians in the epicenter zone took part in emergency relief care for children. The investigations of major injuries and diseases in children were taken.

Methods: Demographic data collected included (if possible) age, date of presentation, injury, disease, and surgery performed.

Results: Total casualties were estimated over 80,000 , and much more injured. Eight hundreds and eight-two inpatients were treated by the relief team during the first 10 days. Of 882 inpatients, $192(21.8 \%)$ were < 18 years old. Children's ages were not evenly distributed. Twenty-seven patients were neonates, infants, and toddlers (14\%), 105 school-aged (55\%), and 60 adolescents (31\%). The admitted children suffered from 256 injures. Limb (106 cases, 55.2\%) and body surface (67 cases, $34.9 \%$ ) were the majorly injured locations. 127 cases $(66.2 \%)$ had simple, open injures and 106 (55.2\% had fractures. The children's conditions were evaluated as mild $(121,63.0 \%)$, moderate (56, $29.7 \%)$, severe $(8,4.2 \%)$, and fatal $(7,3.7 \%)$.

Conclusions: More than $20 \%$ of patients requiring hospitalization were children. School-aged children were heavily injured. The increase of infectious diseases followed on. The data shows that there is an immediate need for orthopedic and general surgery skills, and, pediatrician should play an important role in early rescue and subsequently control of infectious diseases in a huge earthquake hazard. 